\title{
8 \\ From traditional to modern management in Fakarava
}

\author{
Lorin Thorax
}

\section{Fakarava: A protected atoll}

Fakarava is the second largest atoll of the Tuamotu Archipelago in French Polynesia. The atoll encompasses a 60-kilometre-long and 25-kilometre-wide lagoon. The surrounding reef only forms a barrier to the ocean in the north-east and the south-east. The rest of the periphery consists of a partially emerged coral plate, which leaves the lagoon in direct contact with the ocean by many hoa (small passages between the coral plates). The atoll contains two reef passes (deep and wide openings of the reef, where the most important flow between the lagoon and the ocean occurs). The first one, Garuae, in the north-west, is relatively closely located to the main village Rotoava. The Tumakohua pass, in the south, is much smaller and is located near the old village of Tetamanu, which housed the atoll's first inhabitants. Inhabited by about 600 people in 2007, the atoll is considered by the Polynesians as an authentic and natural destination, populated by the traditional Paumotu (inhabitants of the Tuamotu Archipelago) and their culture. Spared from mass tourism, the local population has preserved the environment by using it in a sustainable and conscientious way. This exemplary behaviour has resulted in international recognition, in particular, when the atoll was declared a biosphere reserve 
by UNESCO in November 2006. Thus, management and exploitation of natural heritage today is governed by official institutions that work closely with the population.

The main economic activities on the atoll are tourism (particularly tourism related to scuba diving), pearl culture, copra (dried coconut flesh) and, to a lesser extent, fishing (which remains a means of subsistence that is rooted in the local micro-economy). Recently put on the global map by the construction of an airport and a new port, Fakarava attracts an increasingly high number of tourists, which provides new opportunities for residents, but also new issues related to exploitation of the lagoon. Anthropogenic pressure on atoll ecosystems is growing and management models set up by UNESCO and the PGEM (Plan de Gestion de l'Espace Maritime, or Marine Space Management Plan) have been employed to optimise operation and natural-resource management. They do so by involving the population in the decisionmaking process and by raising awareness of the environmental issues arising from the introduction of modern and Western concepts.

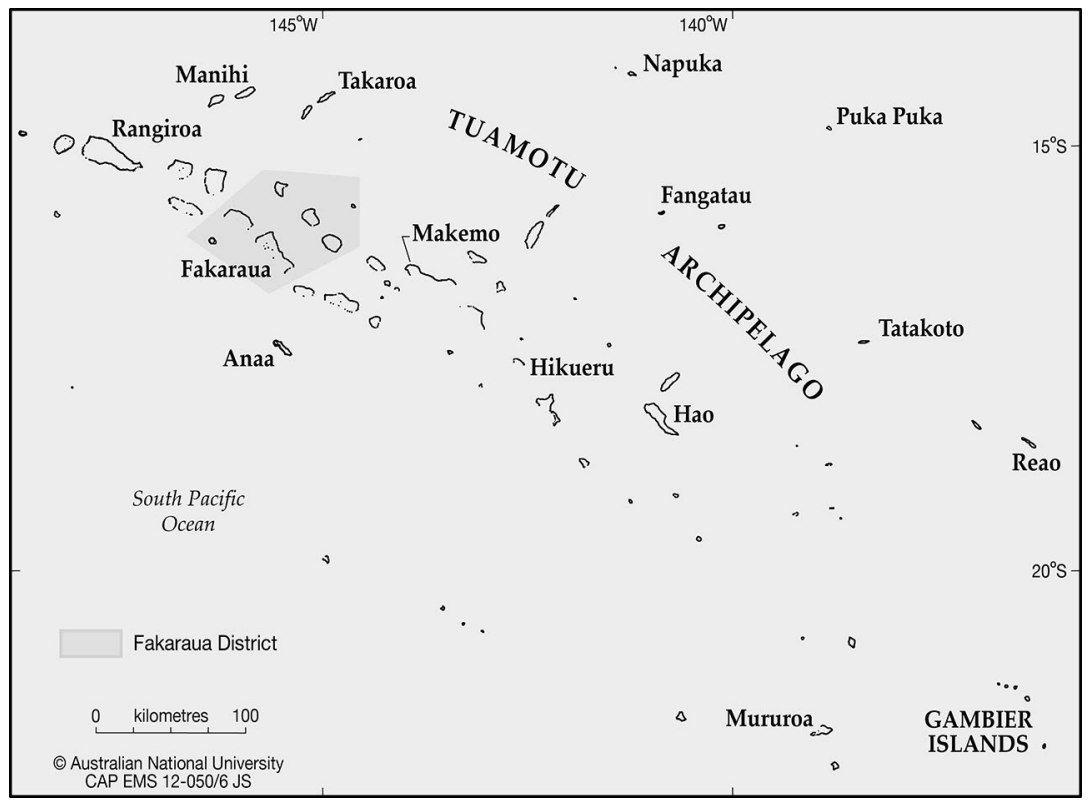

Figure 20: Map of Fakarava in the Tuamotu Archipelago

Source: (C) The Australian National University CAP EMS 12-050/6 JS 


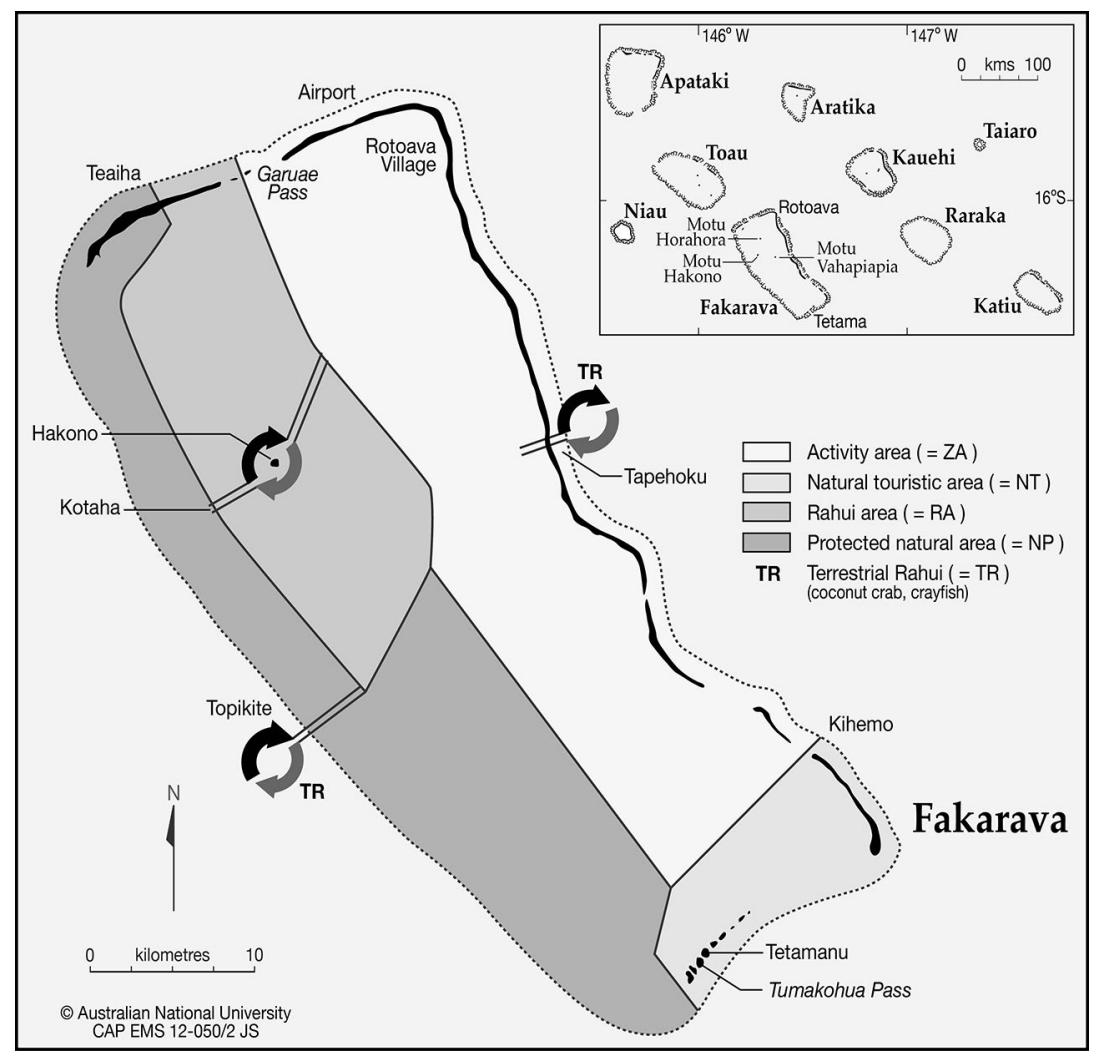

Figure 21: Map of Fakarava with the rahui areas

Source: (C) The Australian National University CAP EMS 12-050/2 JS

The remaining question is whether these models are adapted to the local culture and the way of life on an atoll. The study of traditional farms and representations of nature by the Paumotu is essential for assessing the degree to which locals and their culture have adapted to these changing circumstances. It is important to understand how the circumstances of life on an atoll can affect the social, economic and environmental development of the local community or, in other words, to understand the cultural impact it has. Insularity is strong in Polynesia and isolation is especially felt in the Tuamotu Archipelago and other outer islands.

Another aspect that influences life on an atoll is its limited land area. Resources are restricted and demand can only be modified by demography or opportunities for travel. These constraints cause 
complex social issues and the emergence of cultural specificities that are related to the phenomenon of isolation and inherently associated with the life on an island. Thus, the limitation of resources inevitably leads to social adjustments and cultural events, such as specific forms of rahui that are the main topic of discussion in this chapter.

An atoll is a fragile and precarious ecosystem. Fakarava's lagooncentred ecosystem is much less hospitable to human habitation than higher islands, which have more land and mountains to catch moisture-laden clouds. The strength of the ocean imposes itself from the periphery of the island and from the lagoon, linked as they are through passes and channels, which provide the lagoon with its water and fauna. Human life is only possible on the motu perched atop the reef surrounding the lagoon. As Bachimon notes, 'with atolls, we are at the limit of the concept of island, as differentiation from the ocean environment is slim. There cannot be insular oceanicity more powerful than on an atoll'. ${ }^{2}$ Here, Bachimon's notion of insularity is virtually swept away to be replaced by an even stronger concept, absolute oceanicity. From the biological point of view one must stress, however, the great biodiversity of atolls, which makes them oases in the middle of the ocean. While atoll's terrestrial biodiversity is relatively poor, their marine biodiversity is generally extremely rich.

Fakarava's lagoon ecosystem is prolific and therefore provides islanders with plentiful resources. Whether using its coral and shells, for food consumption or handcraft use, crustaceans or many species of fish, the Paumotu knew the full use of marine resources - their whole culture is oriented towards their use.

\section{Reappropriation of the rahui concept}

This chapter analyses the practice of rahui throughout pre-colonial, colonial and modern times, in order to describe the various adjustments to which this practice was subject, particularly in the case of the atolls of the Tuamotu Archipelago in general and Fakarava in particular. What was meant by rahui in the Polynesian context? Generally, the aim of rahui is the conscious management of marine and

\footnotetext{
Motu: a group of islets forming a ring-shaped atoll.

2 Bachimon, P., 1990. Tahiti: entre mythes et réalités. Paris: Ed C.T.H.S, p. 29.
} 
terrestrial resources. It is an institution marked by sacredness and tapu and imposed by community leaders. The rahui, therefore, possesses a religious and sacred dimension prohibiting the exploitation of some resources or a specific area. A rahui could have several functions, one of which was to impose a leader's authority: the more important a rahui was (in its duration or in the size of the area subjected to the rahui), the greater the power of the leader. Secondly, the rahui could act to preserve a certain amount of resources in anticipation of a ceremony, or could simply be imposed to prevent a possible famine. In all events, as the practice of rahui referred to the concepts of tapu, sacredness played an important role. Anyone who did not respect this sacredness could be punished by the gods, such as by misfortune befalling him or his family.

\section{Pre-colonial times}

The atoll dwellers of Fakarava utilised a wide variety of food resources to survive in their relatively poorly endowed habitats. The lean soils of atolls did not allow the growing of crops on a significant scale and the population relied on pits (trenches that were filled with organic waste) to grow fruit trees and root crops. These pits allowed the culture to survive the atoll's extreme weather and hydrogeological conditions. Hence, the main food resources, with the exception of some pig farms, originated from the sea and, more specifically, from the lagoon. In addition, the Paumotu's nomadic lifestyles naturally lead to the rotation of exploited areas. Due to the broad space available, and the lagoon's high biodiversity, the rahui during pre-colonial times was more a way for community leaders to demonstrate their power, than the expression of an ecological consciousness: rahui were laid on areas or species to ensure the abundance of resources for ceremonies. As the small populations did not put pressure on the ecosystem, the rahui was more a means for the leader to enforce and remind the population of the prevailing social and religious rules. The planning and provision of a quantity of resources for ceremonial purposes was the leading reason behind the concept of tapu, which has an important religious dimension. This practice anchored the Paumotu cosmogony in daily life, and reinforced social cohesion around common beliefs. Daily life was governed by rules centred on tapu and other religious bans: the building of a boat, going fishing and other activities, had to be implemented carefully to ensure success and security to 
their participants. The rahui was a practice that fitted the system of local beliefs and logically applied cultural standards in reference to divinities and practices of daily life. Hence, the rahui had sacred and religious dimensions through the tapu, which constituted its essence and provided the rahui with a real legitimacy. Rahui and tapu, in this context, went far beyond the simple management of available resources.

\section{Colonial period}

The practice of rahui took a new dimension during the colonial period when, in the late nineteenth century, French settlers imposed their view of the world and prohibited many indigenous cultural practices. From 1870, Catholic missionaries organised the atolls into intensive coconut cultivation so as to produce copra, which particularly suited the environmental conditions of the region. Thus coconut trees rapidly covered most of the exploitable land surface of the atolls. With evangelisation, loss of cultural references and the decline of local beliefs, the religious connotations of rahui progressively lost their importance and were replaced by new meanings for Paumotu people. These new meanings were more related to the economy. The practice of rahui soon ran according to the economic imperatives for copra production. Indeed, the practice has been diverted from its original use to meet the new French colonial economic guidelines for Polynesians: economy and profits have become the main concerns. Despite a nomadic lifestyle in Fakarava, it became essential to have a main village located on the boat passage (for instance, the village of Rotoava in the north, which is located closer to the great pass) to be the base for harvesting copra bags. This new system did not correspond to traditional values but to the realities of distant markets. The spatial organisation evolved to suit the exploitation of copra and the atoll was divided into three main production zones, with a fourth located on the neighbouring atoll of Toau. These areas were designated based on the productivity of their coconut groves and the entire village population moved from one zone to the other every three months. The copra harvest was delivered to the schooners that regularly connected the atoll with Papeete. This system allowed time for the recovery of coconut plantations. At each new displacement, the population was 
relocated to so-called fare rahui, ${ }^{3}$ which were temporary dwellings. It appears that, despite the division of the atoll's land between four extended families, the rahui were not, at least initially, performed in a competitive way, but rather everyone was involved throughout the year in a collective, communal exploitation of various areas that were considered to be community assets. Thereafter, the importance of profit overtook the sense of community cohesion and every family started to run their areas separately while continuing to synchronise the rotation between zones.

The lagoon's exploitation was performed in parallel with the exploitation of the coconut trees so that the anthropogenic pressure on the lagoon's ecosystem was never too strong. When regulations on compulsory school attendance came into effect, part of the population was forced to stay in the main village. The last official rahui involving mass mobility that took place in Fakarava occurred in July 1975. Thereafter, the women remained in the village making craft objects and caring for children attending school, while men and teenage boys went to harvest and tend to less remote coconut tree fields. The length of stays has become shorter over time, but the social dimension remained important. As the village lifestyle is increasingly Westernised, the return to the coconut fields is seen as a return to traditional Paumotu lifestyle. The links to the family group and to the ancestral land narrow in the sector, and a lifestyle that could be considered an indicator of poverty in the context of the village is claimed as traditional. Currently, periodic visits to the fields involving stays of generally less than two weeks are undertaken by some family members.

\section{Institutional reappropriation}

Recently, the rahui concept has taken a new, ecological direction. New priorities have emerged since the atoll was declared a biosphere reserve. Environmental management is now an important consideration in the development of the atoll, and local and international institutions have proposed and implemented management models to ensure the sustainability of the atoll ecosystem's biodiversity. Three major management models are in operation, each set up by a different entity,

3 Fare rahui: provisional house built in rahui area. 
but which are nonetheless complementary. The first was proposed by the MAB (Man and Biosphere program, associated with UNESCO) on all Fakarava territory, which divides the atoll into three zones: a central area, a buffer zone and a transition area. This model is designed as a tool for sensitising the population and tourists to key ecological considerations. It identifies important areas of biodiversity and biological heritage. The second model, the General Territorial Plan (PGA) applies land management laws and edicts to the land. The third model, the PGEM is the one most concerned with the rahui, and was validated in 2007. This model is the regulatory and legislative tool for the entire marine section of the atoll, from the lagoon to the outside reef slopes. Under the last two plans, management models have been developed: the Urban Department for the PGA and the Fishery Department for the PGEM. The same area may be part of different management models simultaneously, although the PGA and PGEM are legislative tools and are therefore defined by the French Polynesian civil code.

The goal of PGEM is to ensure management of maritime space, both in terms of exploitation of natural resources and the regulation of related human activities. This includes rational utilisation of resources and space, management of user conflicts, control of degradation and pollution of the marine environment, and protection of marine ecosystems and endangered species. The PGEM is thus a document for space management that defines the terms of use, management, support and recovery of the lagoon. The delineation of zoning has been made by means of a strong participatory approach towards the atoll's population, which was actively included in the decisionmaking process. Each activity sector has been consulted to reflect the opinion of each party and the cultural aspect has been prominent in establishing the structure. The space is divided into several zones, which define the procedures and rules for any activity. There are four areas on the lagoon: an activity area, a protected tourist area, a protected natural area and, of particular interest here, a rahui area. This last area is a marine area subject to active management intervention to ensure the maintenance of habitats and to meet the requirements of specific species. The main objectives are to provide communities living near the area with the opportunity to maintain a sustainable lifestyle and to focus on research and monitoring environmental management alongside ancestral practices. 
The rahui area is located in the north-western part of the atoll and encompasses about a quarter of the lagoon. It is split into two zones, and each zone is open alternately every two years. When a rahui is promulgated in one zone by the standing committee (composed mainly of inhabitants of the atoll), fishing (fish only) is prohibited in the whole zone. Simultaneously, fishing is allowed in the second zone. There is a second type of rahui that concerns particular species. All species of lobster and the coconut crabs (kaveu) are protected across the atoll, which is also divided into two parts by a north-south border and open alternately every two years. This latter, land-based rahui completes the marine rahui. The enforcement of these rahui follows a conservation and preservation focus on, on the one hand, the environment and, on the other hand, on cultural practices inherent in the operation of this ecosystem.

The development of the PGEM not only took the richness and diversity of lagoons into account, but also, most importantly, the needs of the population. It is possible to enumerate several dimensions of rahui practice as it is formulated by institutions. There is, firstly, an ecological dimension aimed at the conservation of biological heritage, which is directly linked to the new issues of tourist-based development, and therefore economic development of the atoll. Secondly, a strong ethical vision pervades the system as it reconciles economic and social development of the population while preserving the environment at the base for the perpetuation of local and cultural traditions.

There is another type of rahui, imposed by the Fisheries Department that applies across French Polynesia concerning only certain species. The system has two operating periods during the year: a period during which the rahui regulates fishing activities and imposes a minimum size for species in order that they can reproduce at least once during their lives; and a period of tapu, which prohibits exploitation, trade and consumption of targeted species. There is, in these systems, an important contradiction to the sense of the word rahui: the PGEM implies a total prohibition of the use of resources on demarcated areas; whereas the Fisheries Service uses the word rahui for a period of legal and regulated operation, in parallel with a complete ban on operations during the tapu phase. The vagueness in the terms used and the overlay of local and national models has often made it difficult for the local population to understand and conform to the restrictions. 
The reappropriation of the term and concept of rahui by government institutions demonstrates their determination to integrate, respect and value traditions and local cultural practices. But it appears that, due to a lack of information and communication from government, the majority of the population prefers to dismiss the model rather than to try to understand and adhere to it. It is perhaps too simplistic to suggest that the term rahui loses some of its meaning when used by government institutions, but it is undeniable that the reappropriation of the concept must be adjusted for, and maybe simplified to fully convince, the local population, who currently refuse to acknowledge it. During my fieldwork, I realised that the population was very poorly informed on this topic and that the PGEM was primarily understood as a ban. Indeed, most fishermen saw the rahui only as a means by the government and institutions to control their activities and therefore to reduce their freedom of action. This is, however, clearly not the purpose of PGEM, which only aims to manage and organise the harmonious ecological development of the lagoon by enforcing these new rules.

Our discussions with the different parties have revealed that many inhabitants did not know of the existence of these management regimes or, if they knew, they were not aware of the location of regulated areas. Lagoon users, because of their lack of information on this topic, prefer then to ignore the rules and continue to fish as they have always done. The size of the lagoon makes it difficult to control these activities. Self-control is the chief means of compliance advocated by the authorities, but it is rarely practiced because, in such a small population, family and friendship networks cancel its efficiency. The rahui within PGEM raises issues, as it refers to a practice that makes little sense to people who are supposed to implement and respect it, because respecting something in which they don't believe is not possible. And that is certainly the main issue of PGEM and of its rahui areas: the Paumotus do not believe anymore in the sacredness of the practice and the lagoon. 
This text is taken from The Rahui: Legal pluralism in Polynesian traditional management of resources and territories, edited by Tamatoa Bambridge, published 2016 by ANU Press, The Australian National University, Canberra, Australia. 